\title{
Covalent immobilization of tyrosinase onto multi-walled carbon nanotubes and its potential use in phenol biosensing
}

\author{
Shafinaz Shahir ${ }^{\text {** }}$, Tai Boon $\mathrm{Kai}^{2}$, Zaiton Abdul Majid ${ }^{3}$, Nor Aziah Buang ${ }^{4}$ \\ ${ }^{1,2}$ Department of Biological Sciences, Faculty of Biosciences \& Bioengineering, Universiti Teknologi Malaysia 81310, UTM Skudai, Johor, Malaysia, \\ ${ }^{3,4}$ Department of Chemistry, Faculty of Science, Universiti Teknologi Malaysia 81310, UTM Skudai, Johor, Malaysia, \\ Received 26 April 2011, Revised 10 May 2011, Accepted 10 May 2010, Available online 28 June 2011
}

\begin{abstract}
The possibility of modifying the surface properties of multi-walled carbon nanotubes (MWCNTs) has stimulated increasing interest in their application as components in biosensors. In this study the enzyme tyrosinase was immobilized onto functionalized MWCNTs (fMWCNTs) via covalent bonding and activity of immobilized tyrosinase was measured via electrochemical detection of phenol. MWCNTs were first treated with sulphuric acid and nitric acid with ratio $1: 3$ at $70^{\circ} \mathrm{C}$ to introduce carboxylated groups (-COOH). The carboxyl moieties were then activated by treatment with a cross-linker, 1ethyl-3-(3-dimethylaminopropyl) carbodiimide (EDC) to enable tyrosinase immobilization via amide bonding. FTIR spectra of tyrosinase immobilized-f MWCNTs showed the presence of peaks attributing to aliphatic C-N and amide carbonyl stretching modes which confirmed successful covalent immobilization of tyrosinase onto fMWCNTs. Electrochemical measurements using tyrosinase-fMWCNTs-CPE revealed increasing limiting current values of reduction peak with increasing phenol concentrations at $-200 \mathrm{mV}$. This study has demonstrated the potential of using MWCNTs as support for enzyme immobilization and their application in biosensor technology.
\end{abstract}

| Tyrosinase | Multi-walled carbon nanotubes | Biosensor | 1 -ethyl -3-(3-dimethylaminopropyl) carbodiimide | Phenol |

( 2011 Ibnu Sina Institute. All rights reserved. http://dx.doi.org/10.11113/mjfas.v7n1.242

\section{INTRODUCTION}

Carbon nanotubes (CNTs) has stimulated great interest among researchers in various disciplines such as electronics, engineering, surface chemistry, biomedicine, as well as bioscience [1]. The reason for the widespread interest is that carbon nanotubes exhibit unique structural, electrical, mechanical, electrochemical, excellent chemical properties as well as thermal stability [2-3]. There are two main families of CNTs, namely single-walled (SWCNTs) and multi-walled (MWCNTs). SWCNTs are graphite sheet rolled-over into a cylinder with a typical diameter in the order of $1.4 \mathrm{~nm}$ whilst MWCNTs consist of multiple concentric graphite with an interlayer spacing of $3.4 \AA$ and a diameter typically in the order of 10-20 nm [1].

A viable biosensor should exhibit high enzymatic activity, fast electron transfer kinetic to provide fast response time, high loading of biomaterial, high selectivity and accuracy. To intimately connect a biomaterial to a transducer surface a number of immobilization methods can be employed such as adsorption, encapsulation, electropoly-

*Corresponding author at: Department of Biological Sciences, Faculty of Biosciences \& Bioengineering, Universiti Teknologi Malaysia 81310, UTM Skudai, Johor, Malaysia

E-mail addresses: shafinaz@fbb.utm.my/shafinazshahir@utm.my merization, cross-linking and covalent bonding [4-6]. Once the biomaterial is immobilized, the transducer is able effectively convert the physico-chemical changes in the biologically active material resulting from the interaction with its analyte into an output signal. The signal produced is proportional to the amount of analyte in the system being tested. However, the physiological electron transfer process is heterogeneous and may slow down communication between the enzyme and transducer. Needless to say the enzyme immobilization step is critical, since the biomaterial has to remain active to perform an efficient biorecognition of the analyte. A review by Rivas et al. [7] reported general strategies for the development of carbon nanotubes based electrochemical enzymatic biosensor. These strategies include non-covalent functionalization of the sidewall of SWCNTs and covalent functionalization via carbodiimide chemistry. Dai and co-workers presented non-covalent functionalization of CNTs side-wall for the efficient immobilization of ferritin, streptavidin, and biotinyl-3,6-dioxaoctanediamine [8] whilst Gooding et al. presented a covalent functionalization strategy for studying the electron transfer properties of redox enzyme [9]. Recent work by Wang et al. using covalent grafted tyrosinase on $\mathrm{Au}$ electrode demonstrated excellent amperometric response to phenolic compounds with sensitivity higher than that of other reported biosensors [10]. 
Tyrosinase enzyme is grouped into the monophenol monooxygenase (EC 1.14.18.1) class of enzymes. It has been known for some time that this enzyme is essential for melanization. Tyrosinase catalyzes two distinct oxidation reactions in phenol treatment. In cycle 1, tyrosinase accomplishes the oxidation of monophenol to $O$-diphenol. The $O$-diphenol further oxidizes to $O$-quinone in cycle 2 [11]. Molecular oxygen is required in both cycles to accomplish the oxidation reaction. The product, $\mathrm{O}$-quinone reacts spontaneously with one another to form insoluble oligomer via oligomerization that can be removed by filtration [12].

Several literature describing the amperometric detection of phenol derivatives with tyrosinase-modified electrodes have been reported in the last decade [13]. For example, a tyrosinase based modified ITO electrode with poly (GVPB)-g-MWCNTs and poly (HEMA)-g-MWCNTs was fabricated for detection of phenolic compounds in red wines [10]. The study revealed that the tyrosinase based modified ITO electrode with poly (GVPB)-g-MWCNTs and poly (HEMA)-g-MWCNTs were able to sense phenol in the concentration range of $0.6-7.0 \mathrm{mM}$ and $0.05-0.35 \mathrm{mM}$, respectively. Conventional electrodes such as glassy carbon (GC) and metal electrode commonly used as substrate material for amperometric or voltammetric analyte detection reportedly display a series of disadvantages, including poor sensitivity and stability, low reproducibility, large response times and a high overpotential for electron transfer reaction [4]. In this study, tyrosinase was chosen as a model enzyme to catalyze the targeted phenol. Phenol, a contaminant usually present in wastewater from industries such as textile, coal conversion, petroleum refinery, and mining, is lethal to aquatic life at concentrations greater than 50 part per billion (ppb) and fatal in human if ingested (1 gram of phenol) [14]. In this work, Tyrosinase was covalently immobilized onto functionalized MWCNTS via carbodiimide chemistry and its bioactivity for phenol oxidation was assessed electrochemically using tyrosinase-. fMWCNTs-CPE.

\section{EXPERIMENTAL}

\subsection{Materials and methods}

The MWCNTs $(90 \%$ purity, diameter of $10-30 \mathrm{~nm}$ ) were purchased from Sun Innovations Inc, USA. Tyrosinase from mushroom Agricus bisporus (E.C.1.14.18.1, 4000 units $/ \mathrm{mg}$ ) was purchased from Sigma Aldrich. Other reagents such as nitric acid $\left(\mathrm{HNO}_{3}\right)$, sulphuric acid $\left(\mathrm{H}_{2} \mathrm{SO}_{4}\right)$, 2- (N-Morpholino) ethanesulfonic acids (MES), 1 -ethyl -3(3-dimethylaminopropyl) carbodiimide (EDC), phenol, EDTA, $\mathrm{K}_{2} \mathrm{HPO}_{4}$ and $\mathrm{KH}_{2} \mathrm{PO}_{4}$ were purchased from Fluka and Sigma Aldrich and of analytical grade.

\subsection{Functionalization and EDC activation of MWCNTs}

Purified sample of MWCNTs (100 mg) was treated with a $40 \mathrm{~mL}$ mixture of concentrated sulfuric acid and nitric acid (ratio $3: 1$ ) by stirring for 3 hours at $70^{\circ} \mathrm{C}$ followed by sonication for another 3 hours. The sample was neutralized, filtered, washed and dried in an oven at $70^{\circ}$ C. EDC activation of the acid treated-MWCNTs was done as previously described [14] with some modifications. First, the acid treated-MWCNTs $(15 \mathrm{mg})$ were resuspended in deionized water by sonicating the mixture for 5 minutes. Then, $8 \mathrm{~mL}$ of a $500 \mathrm{mM}$ MES buffer (pH 6.1) was added to the above suspension and mixed. Under fast stirring, 12 $\mathrm{mL}$ of fresh EDC aqueous solution $(10 \mathrm{mg} / \mathrm{mL})$ was added quickly and the mixture was continuously stirred at room temperature for 30 minutes. The suspension was then filtered through a $0.45 \mu \mathrm{m}$ polyamide membrane and rinsed thoroughly with $50 \mathrm{mM}$ MES buffer ( $\mathrm{pH}$ 6.1) to remove excess EDC.

\subsection{Immobilization of tyrosinase onto functionalized MWCNTs}

The EDC activated-MWCNTs $(1 \mathrm{mg})$ were dispersed in $1.0 \mathrm{~mL}$ of $100 \mu \mathrm{g} / \mathrm{mL}$ tyrosinase solution followed by shaking at $150 \mathrm{rpm}$ at room temperature for 1 hour. The suspension was centrifuged and washed with $50 \mathrm{mM}$ of MES buffer ( $\mathrm{pH}$ 6.1) three times to remove unbound tyrosinase. The amount of tyrosinase bounded was determined spectrophotomerically using Lowry assay $\left(\mathrm{A}_{750}\right)$. The amount of tyrosinase bounded onto EDC activated-MWCNTs was measured by subtracting the amount of enzyme in initial solution from the amount of enzyme in final solution (refer Equation 1).

$\frac{\mu g \text { of enzyme bound }}{m g \text { dry wt of } M W C N T s}=\frac{A-B}{m g \text { drywt of MWCNTs }}$

where $\mathrm{A}=$ enzyme concentration $(\mu \mathrm{g} / \mathrm{mL})$ in initial solution (soluble tyrosinase) $\mathrm{X}$ volume of initial solution. $\mathrm{B}=$ enzyme concentration $(\mu \mathrm{g} / \mathrm{mL})$ in final solution (washing tyrosinase) $\mathrm{X}$ volume of final solution.

The overall covalent immobilization of tyrosinase onto fMWCNTs is illustrated in Figure 1. 


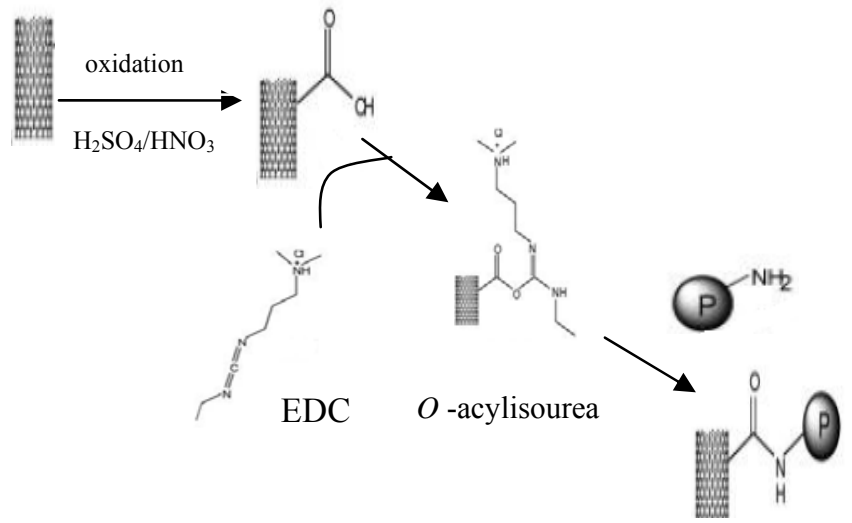

Figure 1: Schematic representation of overall covalent immobilization of tyrosinase onto f MWCNTs.

\subsection{Characterization fMWCNTs and tyrosinase immobilized fMWCNTs}

Sample of commercial MWCNTs, f-MWCNTs (acid treated-MWCNTs and EDC activated-MWCNTs, respectively) and tyrosinase immobilized-f MWCNTs were characterized by Field Emission Scanning Electron Microscope (FESEM) (JEOL 230, Japan) at a magnification range of $10,000 \mathrm{X}$ to $50,000 \mathrm{X}$. These samples were analyzed with carbon tape without further coating. Fourier Transform Infrared (FT-IR) spectra of these samples were recorded in transmission mode in the spectral range of $4000-400 \mathrm{~cm}^{-1}$ using potassium bromide (KBr) disc method. A Perkin-Elmer FT-IR spectrophotometer was used. The EDC activated-MWCNTs and tyrosinase immobilized-f MWCNTs were both characterized with (Electron Dispersion X-Ray) EDX-equipped FESEM (JEOL 230, Japan) to analyze elemental composition of the samples.

\subsection{Electrode Preparation}

Graphite powder, tyrosinase-immobilized fMWCNTs and paraffin oil were mixed in an appropriate weight ratio and mortared to form a homogenous paste. The resulting pastes were packed into the well of the working electrode to a suitable depth. The tyrosinase-fMWCNTs-carbon paste electrode (tyrosinase-fMWCNTs-CPE) was therefore formed. The surface exposed to the solution was polished on a weighing paper to give a smooth finish before use. The body of the working electrode was a Teflon tube $(3 \mathrm{~mm}$ diameter) tightly packed with the tyrosinase-fMWCNTscarbon paste. The electrical contact was provided by a copper wire.

\subsection{Electrochemical measurements}

The catalytic activity of the immobilized tyrosinase was determined electrochemically upon addition of increasing concentrations of phenol. Cyclic voltammograms were recorded using a Mini- and Microelectrode System UM $\mu$ E incorporated with Polar pro software in a three electrode cell system. A silver/ silver chloride, $\mathrm{Ag} \mid \mathrm{AgCl}$ was used as the reference electrode whist Platinum was used as the counter electrode. The working electrode used was the tyrosinase-fMWCNTs-CPE prepared as previously described. All experiments were carried out at room temperature in $25 \mathrm{~mL}$ of $0.1 \mathrm{M}$ phosphate buffer solution $(\mathrm{pH}$ 6.0) with the addition of phenol under magnetic stirring and buffer was used as blank. The cyclic voltammograms of tyrosinasefMWCNTs-CPE were obtained between +14000 to -14000 $\mathrm{mV}$ at a scan rate of $100 \mathrm{mV} / \mathrm{s}$.

\section{RESULTS \& DISCUSSION}

\subsection{Characterization fMWCNTs and tyrosinase immobilized fMWCNTs}

The FT-IR spectra of commercial MWCNTs, acid treated-MWCNTs, EDC activated-MWCNTs and tyrosinase immobilized-f MWCNTs as well as EDC are shown in Figure 2(a) - (c). For both the commercial and acid treated-MWCNTs, the presence of hydroxyl groups $(-\mathrm{OH})$ on the surface are consistent with the peaks observed at $3423 \mathrm{~cm}^{-1}$ and $1066 \mathrm{~cm}^{-1}$ (Fig. 2a) resulting from either ambient atmospheric moisture or oxidation during the purification of MWCNTs [17]. From the spectra of acid treated-MWCNTs, three new peaks appeared at $1166 \mathrm{~cm}^{-1}$, $1550 \mathrm{~cm}^{-1}$ and $1385 \mathrm{~cm}^{-1}$. Peak $1166 \mathrm{~cm}^{-1}$ corresponds to the $\mathrm{C}-\mathrm{OH}$ stretching vibration of the carboxylic groups $-\mathrm{COOH}$ whereas peaks $1550 \mathrm{~cm}^{-1}$ and $1385 \mathrm{~cm}^{-1}$ are attributed to carboxylate anion $-\mathrm{COO}^{-}$on acid treatedMWCNTs. The presence of $-\mathrm{COO}^{-}$is due to $\mathrm{OH}$ bending deformation in $-\mathrm{COOH}$ [18]. All these observations indicate that the surface of the MWCNTs has been functionalized by acid treatment and hence the formation of $-\mathrm{OH}$ and $-\mathrm{COOH}$ groups on MWCNTs.

The acid treated- MWCNTs were further subjected to treatment with EDC in order to enable covalent attachment of proteins. The FT-IR spectra of EDC activated- MWCNTs is presented in Figure 2(b). From the figure, peaks $1550 \mathrm{~cm}^{-}$ 1 and $1385 \mathrm{~cm}^{-1}\left(-\mathrm{COO}^{-}\right)$and $1166 \mathrm{~cm}^{-1}(\mathrm{C}-\mathrm{OH})$ are no longer observed after EDC activation of fMWCNTs. Interestingly, two new peaks appeared at $1631 \mathrm{~cm}^{-1}$ and $1479 \mathrm{~cm}^{-1} ; 1631 \mathrm{~cm}^{-1}$ corresponding to $\mathrm{C}=\mathrm{N}$ (acylisourea) and $\mathrm{C}=\mathrm{C}$ (CNT backbone), and $1479 \mathrm{~cm}^{-1}$ (corresponding to $\mathrm{N}-\mathrm{H}$ bending for amine salt in diimide activated amidated MWCNT). Furthermore, the peak assigned backbone ($\mathrm{N}=\mathrm{C}=\mathrm{N}-$ ) of cross-linker, EDC at $2123 \mathrm{~cm}^{-1}$ was not evident in the EDC activated- MWCNTs. These observations indicated that the carboxyl groups on the acid treated- MWCNTs had been chemically modified with EDC to create reactive groups on the surface. The functional groups - $\mathrm{COOH}$ on the surface of acid treated- MWCNTs require activation before they were able to bond proteins covalently. The carbonyl groups present on the acid treatedMWCNTs were activated by EDC to form an $O$ acylisourea intermediate followed by a nucleophilic 


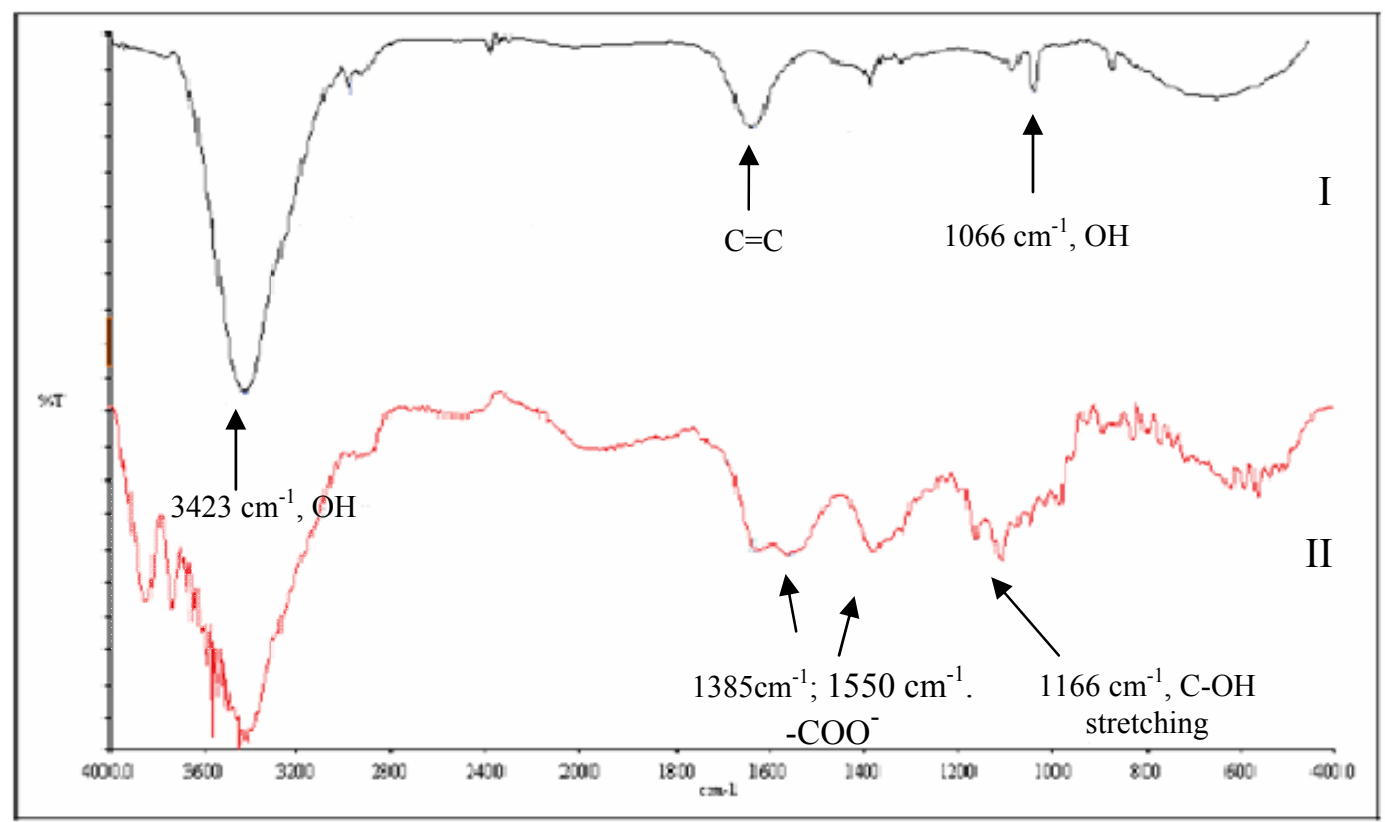

Figure 2(a): $\quad$ FT-IR Spectra of commercial MWCNTs (I) and acid treated-MWCNTs (II).

displacement of the intermediate by the amine to form amide bonding [19]. Chemical activation was required because direct coupling of one functional group to another was not energetically favourable; hence a functional group may need to be reacted with an intermediate compound, in order to be made more reactive [19]. As can be seen from the FT-IR spectra for tyrosinase immobilized-f MWCNTs, a prominent peak pre-dominates at $1382 \mathrm{~cm}^{-1}$ (Figure 2c). Peak at $1382 \mathrm{~cm}^{-1}$ is attributed to the aliphatic C-N vibration suggesting the successful conjugation of tyrosinase onto EDC activated-MWCNTs. A peak at $1639 \mathrm{~cm}^{-1}$ assigned to the amide carbonyl $(\mathrm{C}=\mathrm{O})$ stretching vibration of peptide linkages in the protein back bone was also apparent.
Further evidence for the covalent immobilization of tyrosinase onto fMWCNTs is provided by EDX analysis (Table 1). The EDX analysis of tyrosinase immobilized-f MWCNTs showed the presence of $\mathrm{Cu}(0.77 \%)$. In comparison, no $\mathrm{Cu}$ was detected in the EDC activatedMWCNTs sample without immobilized tyrosinase. Since the tyrosinase active site contains a coupled binuclear copper complex [12], the presence of $\mathrm{Cu}$ in the tyrosinase immobilized-f MWCNTs sample supports the covalent immobilization of tyrosinase onto fMWCNTs.

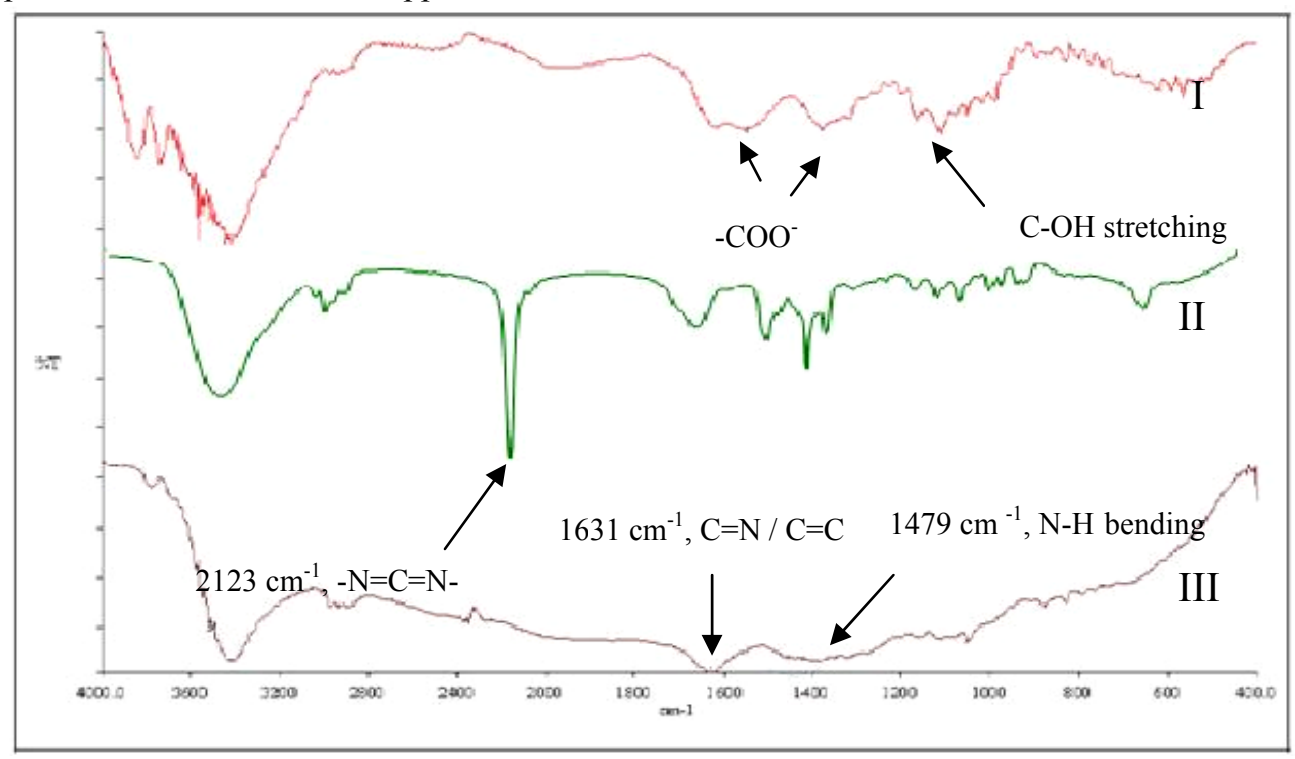

Figure 2(b): FTIR Spectra of acid treated-MWCNTs (I), EDC (II), and EDC activated-MWCNTs (III). 


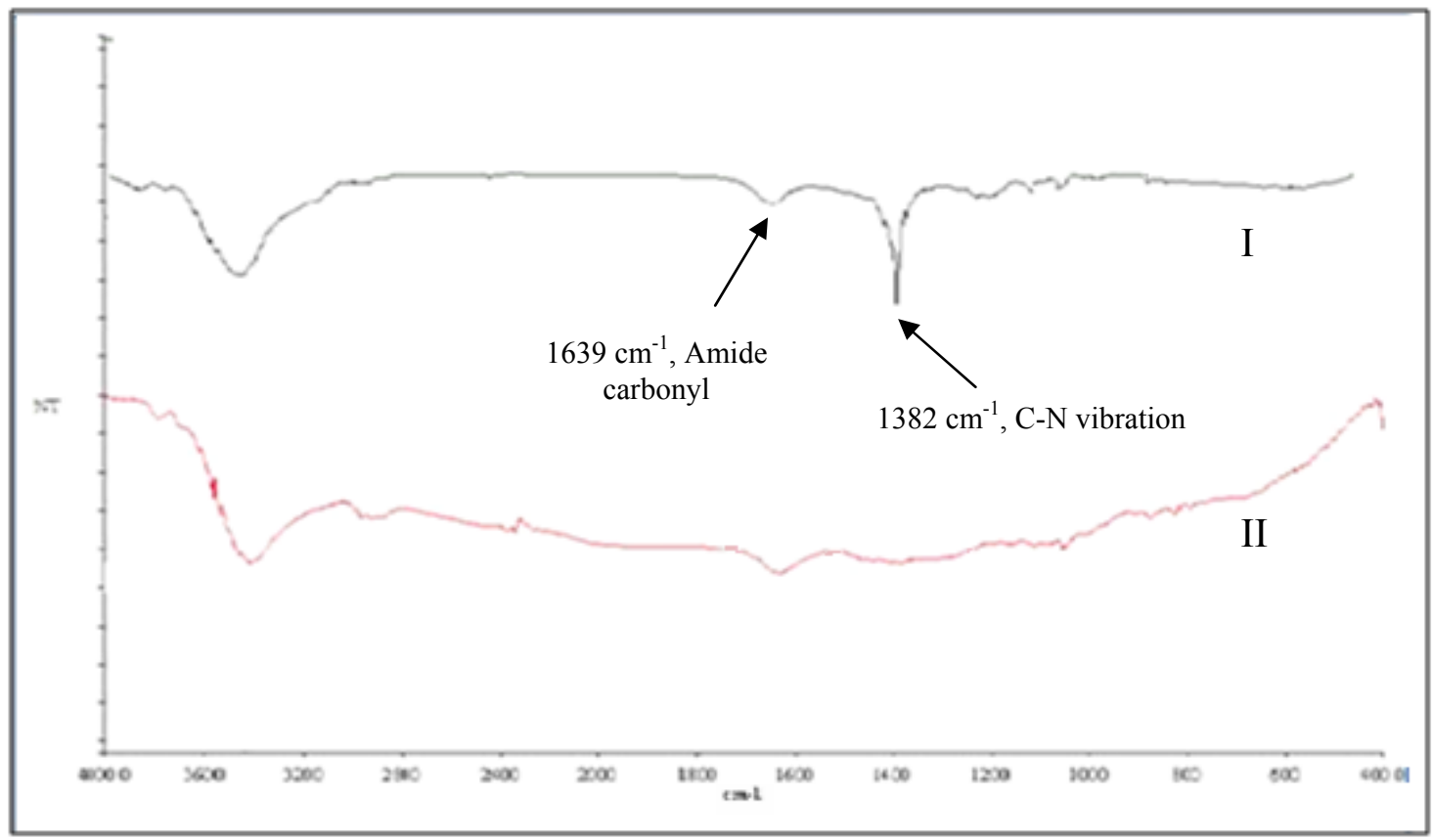

Figure 2(c): FTIR Spectra of tyrosinase immobilized-f-MWCNTs (I) and EDC activated-MWCNTs (II).

The surface morphologies of commercial MWCNTs, acid treated-MWCNTs, EDC activated-MWCNTs and tyrosinase immobilized-f MWCNTS were observed using FESEM. The morphology of commercial MWCNTs appeared as smooth and structured walls as shown in Figure 3a. After acid treatment, the bundle-liked MWCNTs appeared dispersed and white impurities were also noticeable on the surface (Figure $3 b$ ). The introduction of functional groups has been reported to improve the dispersion of MWCNTs [20]. The smooth wall of the nanotubes also became less smooth and slightly bent due to the side attachment of the carboxylic groups during acid oxidation. The noticeable impurities may be due to improper washing during the treatment. Further washing of the fMWCNTs with distilled water and acetone after acid treatment can be done to ensure complete removal of these impurities. After EDC-activation, the 'loose' structure of fMWCNTs appeared to clump together accompanied by swelling of the CNTs as shown in Figure 3c. In comparison, FESEM micrograph of the tyrosinase immobilized fMWCNTs showed the presence of foreign particles on fMWCNTs suspected to be tyrosinase woven onto/enveloping the fMWCNTs threads (Figure 3d). More interestingly, this characteristic was not apparent in the acid treated and EDC activated-MWCNTs. Moreover, the presence of tyrosinase on the fMWCNTs was also confirmed by the EDX analysis (Table 1).
Table 1: Elemental composition of EDC activated-MWCNTs and tyrosinase immobilized-f MWCNTs via oxygen by stoichiometric (Normalized) process option by EDX analysis.

\begin{tabular}{|c|c|c|}
\hline \multirow{2}{*}{ Elemental } & \multicolumn{2}{|c|}{ Elemental weight (\%) } \\
\cline { 2 - 3 } & $\begin{array}{c}\text { EDC activated- } \\
\text { MWCNTs }\end{array}$ & $\begin{array}{c}\text { Tyrosinase } \\
\text { immobilized-f } \\
\text { MWCNTs }\end{array}$ \\
\hline Carbon, C & 26.15 & 22.71 \\
\hline Nitrogen, N & 0.66 & nd \\
\hline Sulfur, S & 0.66 & 6.34 \\
\hline Copper, Cu & nd & $\mathbf{0 . 7 7}$ \\
\hline Oxygen, O & 72.53 & 70.18 \\
\hline Total & 100 & 100 \\
\hline
\end{tabular}

\subsection{Electrochemical measurements}

The Lowry assay was performed to determine the amount of tyrosinase that leached from the fMWCNTs after immobilization. The concentrations of unbound and soluble tyrosinase were determined via Lowry assay as previously described. It was found that $65 \mu \mathrm{g}$ of tyrosinase was covalently attached to $1 \mathrm{mg}$ of EDC activated-MWCNTs representing $65 \%$ immobilization efficiency. However, in order to be used for phenol sensing, the immobilized tyrosinase must possess catalytic activity and this was ascertained by electrochemical measurements where the tyrosinase immobilized-f MWCNTs was used as a working electrode to detect phenol. In a typical three-electrode electrochemical system, tyrosinase-fMWCNTs-CPE was 
(a)

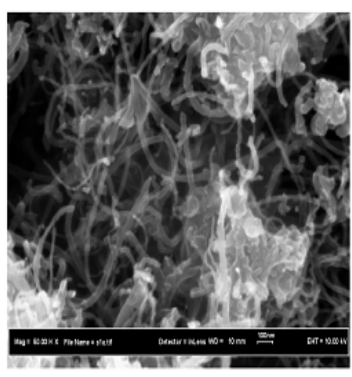

(b)

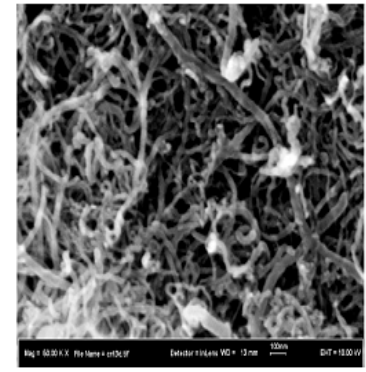

(c)

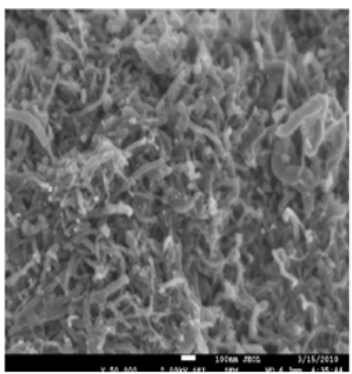

(d)

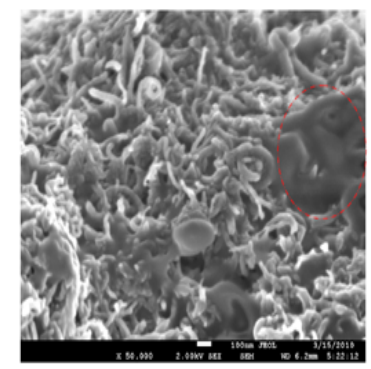

Figure 3: FESEM images of commercial MWCNTs (a), acid treated-MWCNTs (b), EDC activated-MWCNTs (c) and tyrosinase immobilized-f MWCNTs (d) with magnification $50,000 \mathrm{X}$.

used as the working electrode, platinum was used as counter electrode and a $\mathrm{Ag} \mid \mathrm{AgCl}$ electrode acted as reference. Cyclic voltammetric experiments were carried out at $25^{\circ} \mathrm{C}$ and in $\mathrm{pH}$ 6.0, phosphate buffer solution $(0.1 \mathrm{M})$. After adding phenol to the buffer solution, the cyclic voltammogram reflected an increased reduction current at about $-200 \mathrm{mV}$ (Figure 4). This peak represents the production of catechol from the enzymatic reaction in phosphate solution. Table 2 shows the limiting reduction currents at two different phenol concentrations (74 $\mathrm{nA}$ and $441 \mathrm{nA}$ for $0.10 \mathrm{mmol} / \mathrm{L}$ and $0.30 \mathrm{mmol} / \mathrm{L}$ of phenol, respectively). Under the catalysis of the tyrosinase on the electrode surface, the phenol was oxidized by the dissolving oxygen to form $O$-quinone and then reduced into catechol in the following steps :

$$
\begin{aligned}
& \text { Phenol }+ \text { tyrosinase }\left(\mathrm{O}_{2}\right) \longrightarrow \text { catechol } \\
& \text { Catechol }+ \text { tyrosinase }\left(\mathrm{O}_{2}\right) \longrightarrow \text { Eq. } 2 \\
& \text { O-quinone }+2 \mathrm{H}^{+}+2 \mathrm{e}^{-} \longrightarrow \text {-quinone }+\mathrm{H}_{2} \mathrm{O}
\end{aligned}
$$

The appearance of the reduction current therefore indicates that the immobilization process retained the catalytic activity of the immobilized tyrosinase in the modified carbon paste working electrode.

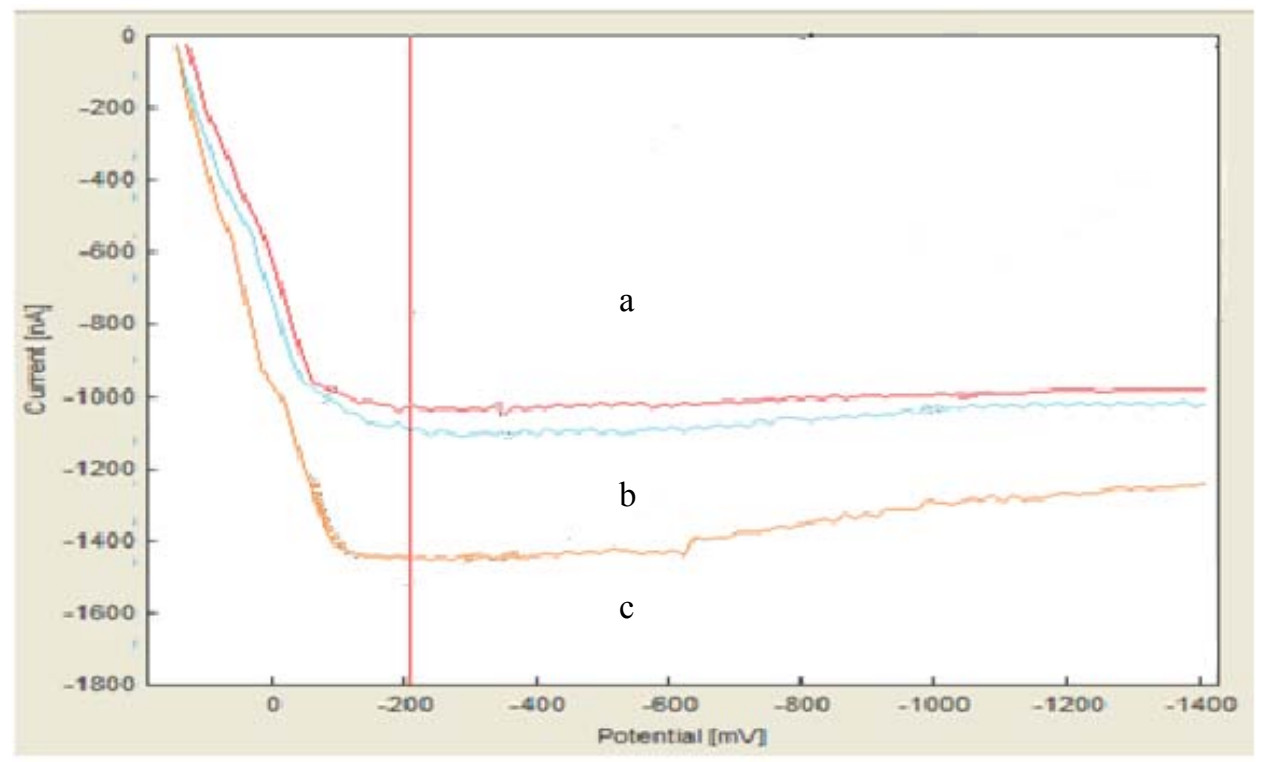

Figure 4: Cyclic voltammograms of tyrosinase-fMWCNTs-CPE in $0.1 \mathrm{M}$ phosphate buffer with $0.1 \mathrm{mmol} / \mathrm{L}$ (b) and $0.3 \mathrm{mmol} / \mathrm{L}$ (c) phenol, respectively at scan rate $100 \mathrm{mV} / \mathrm{s}$ whilst (a) represents blank $(0.1 \mathrm{M}$ phosphate buffer without phenol). 
Table 2: Limiting reduction currents of two different phenol concentrations.

\begin{tabular}{cc}
\hline Phenol concentration, $\mathbf{m m o l} / \mathbf{I}$. & Current value, $\mathbf{n A}$ \\
\hline 0 & 0 \\
0.1 & 74 \\
0.3 & 441
\end{tabular}

\section{CONCLUSION}

This work has demonstrated the attachment of tyrosinase onto functionalized MWCNTs via covalent bonding by carbodiimide chemistry. An enzyme loading of $0.65 \mu \mathrm{g}$ per mg of support was achieved within just 1 hour. Electrochemical measurements using tyrosinase-f MWCNTs-CPE also implied that immobilized tyrosinase is linked to the fMWCNTs surface with bioactivity for phenol oxidation

\section{ACKNOWLEDGEMENT}

We would like to thank the Ministry of Higher Education (MOHE), Malaysia for funding this project under Fundamental Research Grant Scheme (Vot Number 78318) and UTM for providing research facilities.

\section{REFERENCES}

[1] H. Dai, Carbon nanotubes: Opportunities and challenges, Surface Science, 500, (2002), 218-241.

[2] D.H.Lin , and B.S.Xing, Tannic acid adsorption and its role for stabilizing carbon nanotubes suspensions, Environ. Sci. Technol, 42 (2008), $5917-$ 5923.

[3] W.Yang, P.Thordarson, J.J.Gooding, S.P.Ringer, and F.Breet, Carbon nanotubes for biological and biomedical applications, Nanotechnology, 18 (2007).

[4] K. Balasubramanian, and M.Burghard, Biosensors based on carbon nanotubes, Anal Bioanal Chem, 385, (2006), 452-468.

[5] N.Duran, M.A.Rosa, A.D'Annibale, and L.Gianfreda, Application of laccases and tyrosinase (phenoloxidases) immobilized in different supports: A Review, Enzyme and Microbial Technology, 31, (2002), 907-931

[6] P.Liu, Modification of carbon nanotubes with polymers, European Polymer Journal, 41, (2005), 2693-2703.

[7] G.A.Rivas, M.D.Rubianes, M.C. Rodriguez, N.F.Ferreyra, G.L.Luque, M.L.Pedano, S.A. Miscoria, and C.Parrado, Carbon nanotubes for electrochemical biosensing, Talanta, 74 (2007), 291-307.

[8] H.Dai, Y.Zhang, D.Wang, and R.J.Chen, Noncovalent Sidewall Functionalization of Single-Walled Carbon Nanotubes for Protein Immobilization, J. Am. Chem. Soc., 123(2001), 3838-3839.

[9] J.J.Gooding, R.Wibowo, J.Liu, W.Yang, D.Losic, S. Orbons, F.J.Mearns, J.G.Shapter, and D.B.Hibbert, Protein Electrochemistry Using Aligned Carbon Nanotube Arrays, J. Am. Chem. Soc., ( 2003), 9006-9007.

[10] L.Wang, Q.Ran, Y.Tian, S.Ye, J.Xu, Y.Xian, R.Peng and L.Jin, Covalent grafting tyrosinase and its application in phenolic compounds detection, Microchim Acta, (2010), 217-223.

[11] C.Vedrine, S.Fabiano and C.Tran-Minh, Amperometric tyrosinase based biosensor using an electrogenerated polythiophene film as an entrapment support, Talanta, 59 (2003), 535-544.

[12] S.Wada, H.Ichikawa, and K.Tatsumi, Removal of phenols from wastewater by soluble and immobilized Tyrosinase, Biotechnology and Bioengineering, 42, (1993), 854-858.

[13] H.Notsu, T.Tatsuma and A.Fujishima, Tyrosinase-modified boron-doped diamond electrodes for the determination of phenol derivatives, Journal of Electrochemical Chemistry 532, (2002), 86-92.

[14] G.Seetharam and B.A.Saville, Degradation of phenol using tyrosinase immobilized on siliceous supports, Water Research, 37, (2003),436-440.

[15] K.Jiang, L.S. Schadler, R.W. Siegel, X. Zhang, H. Zhang and M. Terrones, Protein immobilization on carbon nanotube via a two-step process of diimide-activated amidation, Journal of Material Chemistry, 14(2003), 37-39.

[16] J. Kathi and K.Rhee, Surface modification of multi-walled carbon nanotubes using 3-aminopropyltriethoxysilane, Journal of Materials Science, 43(2008), 33-37.

[17] C.Cai, J.Chen, and T. Lu, Direct electron transfer of glucose oxidase on the carbon nanotube electrode, Science in China Series B: Chemistry, 47(2004), 113-119.

[18] K,Kalantar-zadeh and B. Fry, Nanotechnology-Enabled Sensors. USA: Springer Science+Business Media. (2008), 374-380.

[19] F.H.Gonjoy, J.Nastalczyk, Z.Roslaniec, and K.Schulte, Surface modified multi-walled carbon nanotubes in CNT/epoxy-composites, Chemical Physical Letter, 370 (2003), 820-824. 